\title{
General anesthesia with remifentanil for Cesarean section in a parturient with an acoustic neuroma
}

Julie M. Bédard MD FRCPC, Michael G. Richardson MD, * Richard N. Wissler MD PhD* $\dagger$

Purpose: To describe the anesthetic management of a parturient with a large acoustic neuroma undergoing general anesthesia with remifentanil for Cesarean section.

Clinical features: A near-term parturient presented with a large intracranial mass. Cesarean section under general anesthesia was elected one week prior to craniotomy for tumour resection. Remifentanil infusion, $0.2-1.0$ $\mu \mathrm{g} \cdot \mathrm{kg}^{-1} \cdot \mathrm{min}^{-1}$, was used from induction to emergence of general anesthesia. The neonate was born seven minutes after the remifentanil infusion was started. She had normal umbilical cord $\mathrm{pH}$ and her Apgar scores were 7 and 8 , at one and five minutes respectively. Although the neonate received supplemental oxygen, she did not require naloxone. Both mother and neonate made an uneventful recovery.

Conclusion: Remifentanil was effective in producing stable hemodynamic conditions, without severe neonatal respiratory depression, during induction and maintenance of general anesthesia for a Cesarean delivery in a parturient with a large intracranial tumour.

Objectif : Décrire la conduite de l'anesthésie générale avec le rémifentanil pour une césarienne chez une patiente enceinte ayant un neurinome acoustique.

Aspects cliniques : Une femme enceinte s'est présentée avec une volumineuse masse intracrânienne quelques semaines avant terme. Une césarienne sous anesthésie générale a été planifiée une semaine avant de procéder à la résection de la tumeur intracrânienne. Le rémifentanil en perfusion intraveineuse a été utilisé de l'induction à l'émergence, à des doses variant de $0.2-1.0 \mu \mathrm{g} \cdot \mathrm{kg}^{-1} \cdot \mathrm{min}^{-1}$. L'enfant est né après sept minutes de perfusion de rémifentanil. Les gaz du cordon étaient normaux et les Apgar à une et cinq minutes étaient respectivement 7 et 8. Malgré l'apport temporaire d'oxygène, le nouveau-né n'a pas eu besoin de naloxone. La mère et l'enfant ont eu une convalescence sans complication.

Conclusion : Le rémifentanil a permis des conditions hémodynamiques stables, sans produire de dépression respiratoire significative chez le nouveau-né, pendant l'induction et la maintenance de l'anesthésie générale pour une césarienne chez une patiente avec une volumineuse tumeur intracrânienne.

From the Departments of Anesthesiology ${ }^{*}$ and Obstetrics \& Gynecology, $\dagger$ University of Rochester School of Medicine and Dentistry, Box 604, Strong Memorial Hospital, 601 Elmwood Avenue, Rochester NY 14642. USA.

Address correspondence to: Dr. Julie M. Bédard, Département d'Anesthésie, Centre Hospitalier Universitaire de Québec, Pavillon SaintFrançois d'Assise, 10, Rue de l'Espinay, Québec City, Québec, Canada, GlL 3L5. Phone: 418-525-4410; Fax: 418-525-4434; E-mail: jbedar@globetrotter.net

Accepted for publication March 17, 1999 


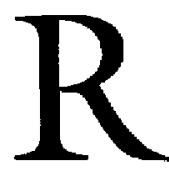

EMIFENTANIL provides profound analgesia, yet it has a unique pharmacokinetic profile with a very short context- sensitive half-time. ${ }^{1}$ This characteristic may make it a useful drug in the management of certain difficult obstetric cases requiring general anesthesia, potentially minimizing the risk or duration of opioid-induced neonatal respiratory depression. The role of remifentanil in obstetric anesthesia remains to be determined, although two recent reports describe the use of remifentanil in a clinical setting. ${ }^{2-3}$ We present the use of this drug as a component of general anesthesia for elective Cesarean delivery in a near-term gravida with a large intracranial mass.

\section{Case Report}

A 30 yr-old G2P1 parturient was investigated for progressive right facial numbness over two months and waning right auditory function over four years. A right acoustic neuroma was diagnosed at 34 wk gestation. Magnetic resonance imaging (MRI) showed a large mass at the right cerebello-pontine angle $(3.8 \mathrm{~cm} \times$ $3.8 \mathrm{~cm} \times 3.8 \mathrm{~cm}$ ) with a component involving the internal auditory canal (Figure 1). The tumour compressed the pons, midbrain and fourth ventricle, which were displaced to the left. There was no evidence of rostral hydrocephalus. The patient denied any neurological symptoms other than the initial complaints, and her neurological examination correlated with her symptoms.

The parnurient was scheduled to undergo Cesarean section with general anesthesia, followed a few days later by craniotomy for resection of the tumour. Preanesthetic evaluation revealed an otherwise healthy 73 $\mathrm{kg}$ woman with a normal airway and an uncomplicated pregnancy at $36 \mathrm{wk}$. She received $50 \mathrm{mg}$ ranitidine and $10 \mathrm{mg}$ metoclopramide iv the night before and one hour prior to Cesarean section. In the operation room, the patient was positioned supine with left uterine displacement and $30^{\circ}$ head elevation. Blood pressure was measured directly with a radial artery catheter. Maternal blood pressure and heart rate were $115 / 68 \mathrm{mmHg}$ and $96 \mathrm{bpm}$, and fetal heart rate $130 \mathrm{bpm}$. The.patient was preoxygenated for four minutes, after which a remifentanil infusion was started at $1 \mu \mathrm{g} \cdot \mathrm{kg}^{-1} \cdot \mathrm{min}^{-1}$ for two minutes. During the infusion, she was reminded to breathe to lead her to slight hyperventilation. Propofol, $100 \mathrm{mg}$, was administered $i v$ and the remifentanil infusion was decreased to $0.2 \mu \mathrm{g} \cdot \mathrm{kg}^{-1} \cdot \mathrm{min}^{-1}$. Cricoid pressure was applied, as consciousness was lost. The lungs were ventilated with positive pressure by mask to induce slight hypocapnia and prevent hypoxemia. Succinytcholine, $120 \mathrm{mg}$, and an additional $50 \mathrm{mg}$

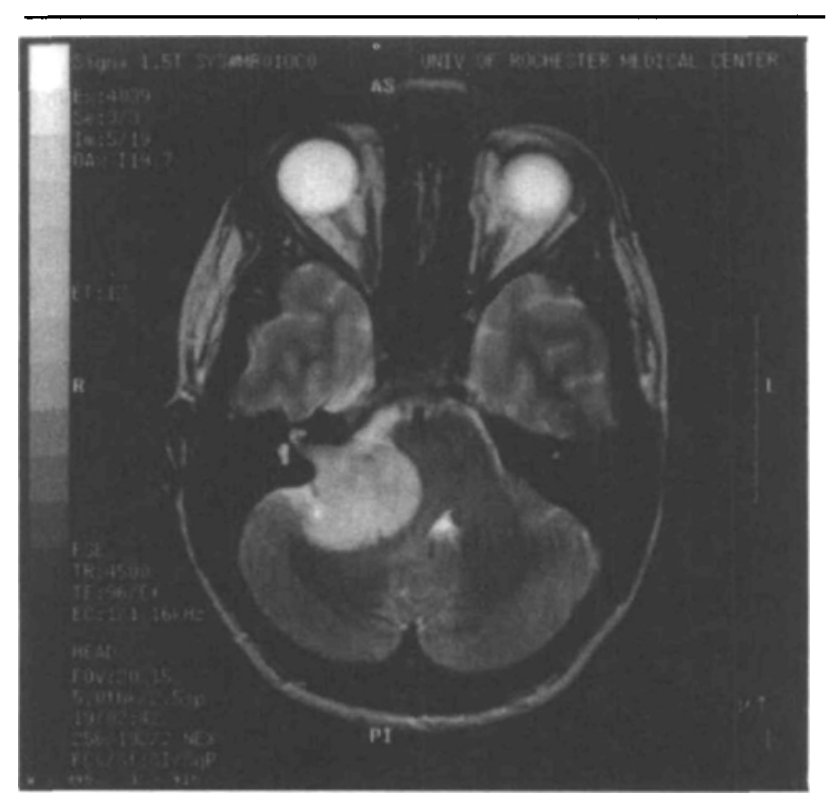

FIGURE I MRI axial T2 weighted image showing a large right acoustic neuroma, leftward shift and compression of the fourth ventricle and surrounding structures.

propofol were given $i$. A transient episode of mild muscle rigidity was observed after induction. However, succinylcholine had just been administered and the episode resolved very quickly. The trachea was easily intubated. The hemoglobin saturation remained $100 \%$ throughout induction. The skin was incised four minutes after induction. Anesthesia was maintained with isoflurane $0.5 \%$ (end-expired concentration) in $0_{2}$ and $0.2-0.3 \mu \mathrm{g} \cdot \mathrm{kg}^{-1} \cdot \mathrm{min}^{-1}$ iv remifentanil. Maternal blood pressure and heart rate remained stable before delivery ranging from 105 to $120 \mathrm{mmHg}$ systolic, 55 to 65 $\mathrm{mmHg}$ diastolic and 95 to $100 \mathrm{bpm}$, except briefly immediately before intubation when her blood pressure was $85 / 50 \mathrm{mmHg}$. After the umbilical cord was clamped, $250 \mu \mathrm{g}$ fentanyl, $30 \mathrm{mg}$ ketorolac and $4 \mathrm{mg}$ ondansetron were administered $i v$ and nitrous oxide $70 \%$ was added. After skin closure, but before emergence, bilateral ilioinguinal and iliohypogastric nerve blocks were performed using bupivacaine $0.5 \%$ with 5 $\mu \mathrm{g} \cdot \mathrm{ml}^{-1}$ epinephrine, $10 \mathrm{ml}$ on each side. Emergence was uneventful and the trachea was extubated. The patient was painfree, responsive and moving all extremities. Satisfactory post-operative analgesia was achieved via iv patient-controlled analgesia using morphine (total of $20 \mathrm{mg}$ in $24 \mathrm{hr}$ ). She experienced no nausea or vomiting during the postoperative period.

Because opioid-induced neonatal respiratory depression was anticipated, a neonatalogist was present at 
delivery. A 2,970 $\mathrm{g}$ female was delivered seven minutes after the remifentanil infusion was initiated. The newborn was crying on the surgical field. Spontaneous ventilation and respiratory efforts were normal without evidence of chest wall retraction or nose flaring. However, because of pale colour, supplemental oxygen was given for two minutes with good response. The arterial umbilical cord $\mathrm{pH}$ was 7.28 and the venous umbilical cord $\mathrm{pH} 7.33$. Her Apgar scores were 7 (-2 colour, -1 tone) and 8 (-1 colour, -1 tone), at one and five minutes respectively. She was taken to the neonatal intensive care unit for observation. Although the baby did not display any sign of clinical respiratory distress with a respiratory rate from 28 to 44 per min and had a normal chest $x$-ray, her initial room air $0_{2}$ saturation was $85-91 \%$. She was placed in a $40 \%$ oxygen tent, but this was discontinued within an hour.

The mother and newborn were discharged home three days later. The mother was readmitted three days after discharge, and underwent uneventful craniotomy with resection of the right acoustic neuroma.

\section{Discussion}

This patient was scheduled for Cesarean delivery at 36 wk to expedite postpartum resection of a large intracranial tumour. The mass effect and nearly obliterated fourth ventricle observed on the MRI film (Figure 1), suggesting decreased posterior fossa compliance, were considered contraindications to neuraxial anesthesia. Therefore, we opted for general anesthesia.

Nineteen patients with acoustic neuroma during gestation have been reported previously. ${ }^{4-9}$ In 12 , the tumours were diagnosed sometime after delivery and were believed retrospectively to be present during pregnancy. ${ }^{4,5}$ Of the remaining seven, only three had increased intracranial pressure. ${ }^{5-9}$ Two had tumour resection before delivery in the second and early third trimester. ${ }^{5,8}$ The other underwent Cesarean delivery at $36 \mathrm{wk}$, two wecks before tumour resection. ${ }^{9}$ However, the details of anesthetic management were not provided.

The main goal when planning general anesthesia for this parturient was to prevent any increase in intracranial pressure. Propofol was used as the anesthetic induction agent because it decreases intracranial pressure in patients with normal and elevated intracranial pressure. Antiemetic prophylaxis with ondansetron was administered after umbilical cord clamping to minimize the possibility of a further increase in intracranial pressure from vomiting. Postoperative analgesia was augmented with bilateral ilio-inguinal and ilio-hypogastric nerve blocks with bupivacaine and parenteral ketorolac to minimize opioid intake and the associated hypercarbia. This analgesic strategy was effective, as reflected by her consumption of only $20 \mathrm{mg}$ morphine over the first 24 hr postoperative period.

Hemodynamic stability is recommended in patients with decreased intracranial compliance during the administration of general anesthesia to prevent further increase in intracranial pressure due to noxious stimuli (e.g. tracheal intubation, surgical incision). This is typically accomplished using opioids. However, in the parturient undergoing a Cesarean section, the risk of neonatal respiratory depression is high. Dann et al. observed no neonatal depression following $10 \mu \mathrm{g} \cdot \mathrm{kg}^{-1}$ alfentanil $i v$ during induction of general anesthesia for Cesarean section in 21 healthy term parturients, and successfully suppressed the hypertensive response to intubation. ${ }^{10}$ However, the same regimen, in 24 preeclamptic preterm parturients, was not as effective in suppressing the hypertensive response to intubation and was associated with considerable neonatal respiratory depression with only three newborn initiating spontaneous ventilation without assistance. ${ }^{11}$ Alfentanil $\left(13.5 \mu \mathrm{g} \cdot \mathrm{kg}^{-1}, 35 \mu \mathrm{g} \cdot \mathrm{kg}^{-1}\right.$ and $\left.125 \mu \mathrm{g} \cdot \mathrm{kg}^{-1}\right)$ $i v$ has been administered during induction of general anesthesia for Cesarean section in three different parturients with severe cardiac disease. ${ }^{12-14}$ The two higher doses caused neonatal respiratory depression with low Apgar scores requiring naloxone and temporary tracheal intubation. ${ }^{13,14}$ The lower dose resulted in a vigorous newborn, but prophylactic naloxone was administered immediately after delivery. ${ }^{12}$ Fentanyl also has been used in doses of $500 \mu \mathrm{g}$ and $1000 \mu \mathrm{g} i \mathrm{D}$ during induction for the same purpose and both doses produced neonatal respiratory depression requiring naloxone administration. ${ }^{15,16}$

In non-pregnant humans, remifentanil has a very short context-sensitive half-time $\mathrm{e}^{\mathrm{a}}$ (3-4 min following a three hour infusion) compared with other piperidine derivatives, including alfentanil $(40-50 \mathrm{~min}){ }^{1}$ Theoretically, this unique pharmacokinetic property may make remifentanil useful in providing stable hemodynamics and minimal neonatal depression during general anesthesia for Cesarean section. Only recently, Gotarten $e t a l$. presented data on remifentanil infusion in pregnant ewes. ${ }^{17}$ Fetal remifentanil plasma concentration reached $14 \%$ of maternal concentration after 15 min infusion. They also concluded that maternal and fetal hemodynamics and acid-base status were not affectecd by remifentanil. Although the United States Food and Drug Administration has not approved the

Context-sensitive balf-time: time required for plasma drug concentration to decrease by $50 \%$ after discontinuation of a drug infusion designed to maintain a constant blood concentration. 
use of remifentanil for the obstetric population, it has been administered to human parturients. ${ }^{2,3, b}$ Remifentanil has been reported to be ineffective in providing labour analgesia in four parturients while leading to episodes of hemoglobin desaturation from 88 to $95 \%$ in three of the four parturients. ${ }^{b}$ In all four, however, it was discontinued long before delivery. Remifentanil has been administered briefly to a parturient to provide effective analgesia during epidural catheter placement, although five hours before she delivered. ${ }^{2}$ Remifentanil infusion and placental transfer have been studied in $\mathbf{1 7}$ human parturients, who underwent elective Csarean delivery with epidural anesthesia and had a concomitant $i v$ infusion of remifentanil $0.1 \mu \mathrm{g} \cdot \mathrm{kg}^{-1} \cdot \mathrm{min}^{-1}$ for at least $15 \mathrm{~min}$ before delivery. ${ }^{3}$ The authors stated they did not observe any neonatal depression, however, three of the 17 newborns had Apgar scores ranging from 4 to 7 at one minute. Criteria for neonatal respiratory depression were not described. Apgar scores at five minutes and neurobehavioral testing at 30 and $60 \mathrm{~min}$ were normal. The umbilical venous to maternal arterial remifentanil ratio was 0.88 , demonstrating considerable placental transfer. The umbilical arterial to umbilical venous remifentanil ratio was 0.29 , suggesting either rapid metabolism or redistribution of the drug in the fetus. The observed umbilical venous to umbilical arterial metabolite ratio of 1.23 suggests the former. We did not analyze blood for remifentanil concentration in the mother or the newborn. The newborn showed no signs of respiratory depression, with normal breathing and heart rate at one and five minutes of life. However, her muscle tone was initially decreased, as evident in the Apgar scores at one and five minutes, and she did require supplemental oxygen during the first hour of life. It is difficult to determine whether these observations were directly attributable to neonatal remifentanil exposure or some other factor(s).

Remifentanil was effective in producing hemodynamic stability during induction and maintenance of general anesthesia for Cesarean delivery in a parturient with decreased posterior fossa compliance. Neonatal outcome was excellent, and no intervention was required other than brief supplemental oxygen administration. The unique pharmacokinetic profile of remifentanil may make it a useful drug in obstetrical situations in which an opioid-based general anesthetic is desirable.

${ }^{b}$ Olufolabi AJ, Penning DH, Wakeling $H$, Glass $P, D e$ Long $L$ Reynolds J. Remifentanil does not provide adequate labor analgesia. Annual Meeting, Society. for Obstetric Anesthesia and Perinatology, Vancouver, Canada, April 29 - May 2, 1998, A58.

\section{Acknowledgment}

The authors thank Paul K. Maurer MD, Department of Neurosurgery, for his assistance in the preparation of this manuscript.

\section{References}

1 Kappila A, Glass PSA, Jacobs JR, et al. Measured context-sensitive half-times of remifentanil and alfentanil. Anesthesiology 1995; 83: 968-75:

2 Brada $S A$, Egan TD, Viscomi CM. The use of remifentanil infusion to facilitate epidural catheter placement in a parturient: a case report with pharmacokinetic simulations. Int J Obstet Anesth 1998; 7: 124-7.

3 Kan RE, Hughes SC, Rasen MA, Kessin C, Preston PG, Lobo EP. Intravenous remifentanil. Placental transfer, maternal and neonatal effects. Anesthesiology 1998; 88: 1467-74.

4 Allen J, Eldridge $R$, Koerber $T$. Acoustic neuroma in the last months of pregnancy. Am J Obstet Gynecol 1974; 119: 516-20.

5 Gaughan RK, Harner SG. Acoustic neuroma and pregnancy. Am J Otol 1993; 14: 88-91.

6 Doyle KJ, Luxford WM. Acoustic neuroma in pregnancy. Am J Otol 1994; 15: 111-3.

7 Magliulo G, Ronzoni $R$, Petti $R$, Marcotullio D, Marini $M$. Acoustic neuroma in the pregnant patient. Eur Arch Otorhinolaryngol $1995 ; 252: 123-4$.

8 Thacker JGM, Wallace EM, Whittle IR, Calder AA. Successful excision of a giant acoustic neuroma in the third trimester of pregnancy. Scott Med J 1995; 40: 117-8.

9 Hsiao CJ, Yang MJ, Hung JH. Acoustic neuroma and twin pregnancy. Int J Gynaecol Obstet 1997; 58: 317-8.

10 Dann WL, Hutchinson A, Cartwright DP. Maternal and neonatal responses to alfentanil administered before induction of general anaesthesia for Caesarean section. Br J Anaesth 1987; 59: 1392-6.

11 Allen RW, James MFM, Uys PC. Attenuation of the pressor response to tracheal intubation in hypertensive proteinuric pregnant patients by lignocaine, alfentanil and magnesium sulphate. Br J Anaesth 1991; 66: 216-23.

12 Field LM, Barton FL. The management of anaesthesia for Caesarean section in a patient with paroxysmal ventricular tachycardia. Anaesthesia 1993; 48: 593-5.

13 Redfern N, Bower S, Bullock RE, Hull CJ. Alfentanil for Caesarean section complicated by severe aortic stenosis. A case report. Br J Anaesth 1987; 59: 1309-12.

14 Batson $M A$, Longmire $S$, Csontos $E$. Alfentanil for urgent Caesarean section in a patient with severe mitral stenosis and pulmonary hypertension. Can J Anaesth 1990; 37: 685-8.

15 Spencer J, Gadalla $F$, Wagner W, Blake J. Caesarean section in a diabetic patient with a recent myocardial infarction. Can J Anaesth 1994; 41: 516-8. 
16 Roberts NV, Keast PJ. Pulmonary hypertension and pregnancy-a lethal combination. Anaesth Intensive Care 1990; 18: 366-74.

17 Gotarten W, Van Aken H, Brodner G, Wüsten R, Marcus MAE. Hemodynamic effects and placental transfer after continuous intravenous application of remifentanil in the chronic maternal-fetal sheep preparation. Anesth Analg 1999; 88: S252. 